\begin{tabular}{|l|l|}
\hline Postprint Version & 1.0 \\
\hline Journal website & $\underline{\text { http://linkinghub.elsevier.com/retrieve/pii/S0738-3991(10)00381-2 }}$ \\
\hline Pubmed link & $\underline{\text { http://www.ncbi.nlm.nih.gov/pubmed/20655164 }}$ \\
\hline DOI & $10.1016 /$ j.pec.2010.06.019 \\
\hline
\end{tabular}

This is a NIVEL certified Post Print, more info at http://www.nivel.eu

\title{
Opinions of patients with type 2 diabetes about responsibility, setting targets and willingness to take medication. A cross-sectional survey
}

\author{
K.J. GORTER ${ }^{A}$, G.H. TUYTEL ${ }^{A}$, J.R.J. DE LEEUW ${ }^{A}$, J.M. BENSING ${ }^{B}$ AND G.E.H.M. RUTTEN ${ }^{A}$ \\ a Julius Center for Health Sciences and Primary Care, University Medical Center Utrecht, The Netherlands \\ ${ }^{\mathrm{b}}$ Nivel Institute, Utrecht, The Netherlands
}

\begin{abstract}
Objective:To assess opinions and their determinants of patients with type 2 diabetes about responsibility for managing their diabetes, setting treatment targets and willingness taking medication.
\end{abstract}

Methods: Questionnaire survey carried out in general practices and outpatient clinics across the Netherlands. Outcomes: opinions about responsibility, targets and medication. Multinomial logistic regression analysis.

Results: Data of 994 consecutive persons were analysed (mean age 65 years; $54 \%$ males). Of these $62 \%$ agreed to take responsibility for their diabetes. In the opinion of $89 \%$ the setting of targets should be by or in cooperation with their physician or nurse and $40 \%$ were willing to take tablets until all targets were attained. Patients who perceived dysfunction by barriers to activity did not agree to take responsibility (OR 3.68; 1.65-8.19). Patients with complications preferred to set targets in cooperation with their physician or nurse (OR 1.98; 1.03-3.80). Males were more willing to take tablets until all targets were attained (OR 1.62; 1.17-2.25).

Conclusion: Not all patients want to take responsibility for their diabetes or taking all necessary tablets, especially those with barriers to activity or complications.

Practice implications: Doctors and nurses should ask for patients' opinions about responsibility and treatment goals before starting education.

\section{INTRODUCTION}

Lifestyle change remains a central part of treatment of type 2 diabetes (T2DM) [1]. The most important choices affecting the health of a person are made by that person, not by health professionals [2]. Therefore, the patient's view on self-management is considered essential in diabetes care [3] and [4]. Self-efficacy is necessary to improve self-management and self-care and has been associated with improved clinical outcomes [5] and [6]. There is debate on the responsibilities of healthcare professionals and patients regarding health counselling and lifestyle change [7]. The general trend has been a gradual replacement of authoritarian and instructive care traditions by patient-centered methods aiming at patient empowerment [8]. Self-management of T2DM has become increasingly the patient's responsibility [9]. On the other hand, diabetes care has been standardized through protocols, guidelines and clinical targets [10]. The treatment 
targets for $\mathrm{HbA1c}$, blood pressure, and lipids are set at stricter levels worldwide, implicating that patients need to take more medication [1]. A variety of factors have been associated with control of blood glucose and cardiovascular risk factors, suggesting that a one-size-fits-all approach to multiple risk factor reduction efforts may not result in attainment of targets [11]. Therefore, individual targets should be tailored for each patient, but to our knowledge negotiating targets with people with T2DM does not routinely occur [12] and [13]. Little is known about the opinions of people with diabetes on relevant topics such as taking responsibility for managing diabetes, the preferred person to determine their personal treatment targets and the willingness to take medication to attain these targets [4]. Therefore, this survey aims to study the association between peoples' opinions about taking responsibility, setting treatment targets and willingness to take medication on the one hand and patients' characteristics and health related quality of life on the other.

\section{METHODS}

In 200780 general practitioners (GPs) and 13 endocrinologists across the Netherlands participated in this study. Over a 3-month period, consecutive patients with T2DM were recruited by their own care providers during regular visits at the practice or outpatient clinic. Patients were asked to complete the questionnaire about their opinions about responsibility for managing diabetes, setting targets and willingness taking medication in the waiting room and to return it anonymously in a prepaid envelope. It was stressed that it was of utmost importance that their opinion should be heard on these topics.

\subsection{Measures}

Our measures were based on qualitative research, that demonstrated variables such as age, weight, metabolic control, medication and distress to be of importance in understanding the patients' role in disease management [4]. The questionnaire started with a short introduction about the background and effectiveness of strict treatment targets. We assessed three different multinomial outcomes: (i) opinion about taking responsibility for managing your diabetes as much as possible: (very much) agree; (very much) do not agree, do not care; (ii) opinion about preferred person to determine your personal treatment targets (HbAlc; blood pressure; total cholesterol): myself, my physician or nurse, in cooperation with my physician or nurse, do not care; (iii) opinion about willingness to take medication to attain treatment targets: until all three targets are attained, one or two of the targets are attained, complaints or side effects arise.

We also assessed possible determinants of the above-mentioned opinions such as age, gender, educational level, ethnicity, setting of diabetes treatment [13], duration of diabetes, diabetes medication, the presence of macro- or microvascular complications and health related quality of life. The latter consists of mobility problems (i.e. problems with walking), self-care problems, pain and anxiety/depression measured by the (also in Dutch) validated EuroQol, general well-being measured by EuroQol-VAS (score range 0-100, where 100 represents best imaginable health status) [14] and three subscales from the (also in Dutch) validated Diabetes Health Profile (DHP-1 score range 0-100, where 100 represents no dysfunction), namely barriers to activity (i.e. impact of having diabetes and demands of treatment on activities of daily living and social functioning), psychological distress and disinhibited eating [15]. Disinhibited eating, or eating disinhibition, refers to the temporary loss of control of eating behaviour because of emotional arousal such as eating when not hungry, overeating and binge eating. [16]. Finally, we measured participants' opinions on perceived glycaemic control, weight and physical exercise, using 5-point Likert scales (range from very poor to very good). The questionnaire was pre-tested and piloted in 10 people with T2DM. Facevalidity was assessed by two physicians, a psychologist and a nurse.

\subsection{Analysis}

Data were analysed using SPSS for Windows (version 12.0.1, SPSS Inc., Chicago, IL, USA). Selfreported categorical outcomes were analysed as percentages.

For the outcome variables we performed three separate multinomial multivariable logistic regression analyses with three dependent variables including one reference. The reference categories were 'do not care' for (i) opinion about taking responsibility for managing your diabetes and for (ii) opinion about preferred person to determine your personal treatment targets and 'until complaints or side effects arise' for (iii) opinion about willingness to take medication to attain treatment targets. By using a backward stepwise method we identified which of the following determinants were independently associated with the 
categorical outcome variables $(p<0.05)$. These were expressed in odds ratios $(\mathrm{OR})$ and their corresponding $95 \%$ confidence intervals $(95 \% \mathrm{CI})$. Possible determinants were analysed as proportions except for age that was analysed as a continuous variable. For use in daily practice, all determinants, except diabetes medication (none; oral glucose lowering agents (OGLA); insulin with or without OGLA use), were dichotomised including ethnicity (Caucasian yes/no), educational level (completed only primary school or less [low] vs. others [high]) setting of diabetes treatment (primary vs. secondary care), duration of diabetes $(<5$ years; $\geq 5$ years), presence of macro- or microvascular complications (yes/no) and also participants' perceived diabetes metabolic control (average/(very) poor vs. (very) good), weight ((much) too low/good vs. (much) too high), physical exercise ((just) enough/(more than) enough vs. (much) too little) and mobility problems, self-care problems, pain/discomfort and anxiety/depression (all: none vs. some/serious). We dichotomised according to the median, results of the EuroQol-VAS (poor vs. good) and the three subscales from the DHP: barriers to activity, psychological distress and eating disinhibition (all: yes/no). Interquartile ranges (25-75\%) were given for extra information. We tested for collinearity by analysing each determinant as an outcome in a regression model; all other determinants were used as independent variables. The setting of diabetes treatment (primary vs. secondary care) was entered in the model as a separate determinant of the outcomes.

\section{RESULTS}

Of 1029 consecutive persons with T2DM who participated, the data of 994 could be analysed. Of these $792(80 \%)$ were mainly treated in primary and the remainder being treated in secondary care. In all, 35 persons could not be included in the analysis since their data were incomplete except for age (mean age 58.2 years; SD 9,8) and gender ( $51 \%$ males). The number of questionnaires returned per practice varied between six and 13 . We have no data of the non-responders. The included participants had a mean age of 65 years (SD 10.3), 54\% were males, $97 \%$ were of a Western ethnicity and $21 \%$ had completed only primary school or less (Table 1). Compared to T2DM patients treated in secondary care, patients in primary care were older, had a shorter duration of diabetes, used insulin less frequently and had fewer complications.

\section{[TABLE 1.]}

\subsection{Opinions}

Of all respondents, $62 \%$ (very much) agreed to take responsibility for their diabetes (Table 2), $48 \%$ preferred the setting of personal targets for $\mathrm{HbA} 1 \mathrm{c} \%$, blood pressure and total cholesterol to be in cooperation with their physician or nurse. These were $68 \%$ and $51 \%$ respectively among participants treated in secondary care,.Of all respondents $45 \%$ were willing to take necessary medication to attain all three targets. This was $48 \%$ among participants treated in primary care

\section{[TABLE 2. ]}

\subsection{Determinants of the patients' opinions}

We did not enter ethnicity as a determinant in the multinomial analysis as fewer than $3 \%$ of the participants were of non-Western ethnicity. We did not find any collinearity between the possible determinants.

\subsubsection{Opinion about taking responsibility for your diabetes}

Among patients who expressed any opinion (agree or not agree) about taking responsibility for their diabetes compared with those who do not care, age, gender, educational level, setting of diabetes treatment, mobility problems, barriers to activity, eating disinhibition and glycaemic control all independently influenced patients' opinions (Table 3). Patients who did not agree to take responsibility perceived dysfunction by barriers to activity (OR 3.68; 95\% CI 1.65-8.19), eating disinhibition (OR 2.41; 1.18-4.95), poor glycaemic control (OR 2.39; 1.16-4.91) and mobility problems (OR 2.28; 1.14-4.54). Among those who agreed to take responsibility were less people with a low educational level (OR $0.57 ; 0.37-0.88$ ), less males (OR $0.59 ; 0.42-0.84)$ and less patients treated in primary care setting (OR $0.59 ; 0.37-0.94)$. 


\section{[TABLE 3].}

\subsubsection{Opinion about preferred person to determine personal treatment targets}

As only less than $2 \%$ of the participants preferred themselves as the person to determine treatment targets, we did not use this outcome in further analysis.

Among patients who expressed an opinion about the preferred person to determine personal treatment targets compared to those who do not care, none of the possible determinants independently influenced patients' opinion, except that patients with complications preferred to determine treatment targets in cooperation with their physician or nurse (OR 1.98; 1.03-3.80) (not in table).

\subsubsection{Opinion about willingness to take medication to attain targets}

Among patients who expressed an opinion about willingness to take medication to attain treatment targets compared to those who are willing to take medication only until complaints or side effects arise, gender, self-reported mobility problems, pain/discomfort and perceived barriers to activity independently influenced patients' opinions. Males were more willing to take tablets until all three targets are attained (OR 1.62; 1.17-2.25), as opposed to those who showed dysfunction by barriers to activity (OR $0.70 ; 0.50-$ $0.98)$, perceived some/serious pain (OR $0.73 ; 0.54-0.98$ ) and with mobility problems (OR 0.46; 0.24-0.88), who were less willing to do so (Table 4).

\section{[TABLE 4.]}

\section{DISCUSSION AND CONCLUSION}

\subsection{Discussion}

Although almost two-thirds of the patients with T2DM agreed to take responsibility for their own diabetes, in the opinion of nine out of 10 people the setting of targets should be done by or in cooperation with their physician or nurse.

Persons with T2DM who are also suffering from mobility problems, barriers to activity, eating disinhibition and poor glycaemic control are less willing to take responsibility for their diabetes. However, females, those with higher education and those treated for their diabetes in primary care setting are more willing to do so. Patients suffering from complications have a preference to determine treatment targets in cooperation with their physician or nurse. Males are more willing to take tablets until all three treatment targets are attained, but persons with perceived some/serious pain/discomfort or dysfunction by barriers to activity are less willing. Age is not a determinant of any of these preferences.

\subsubsection{Taking responsibility}

This study shows that most people with T2DM agree to take responsibility for their illness. Indeed, this underpins the emphasis that diabetes care professionals put on patients' own responsibility for the management of diabetes [7]. The present study shows that even before the stage of discussing selfmanagement and setting treatment goals, doctors and nurses should ask for patients' opinions on responsibility and willingness taking medication, especially in case of complications or co-morbidity.

\subsubsection{Who should determine personal treatment targets}

The majority of the patients in this study wanted to take responsibility for their illness, but most of them did not want to set treatment targets for blood glucose, blood pressure and blood lipids. Indeed, usually patients are asked to take responsibility only for their blood glucose levels [17] and not for the other two targets. Although there is evidence that persons with defined treatment targets have more effective self-care behaviour [18], it was shown recently that less than two-thirds of patients with diabetes and also hypertension had knowledge about their personal blood pressure targets [19]. Besides, qualitative research shows that there is often disagreement between patients and providers on goals and strategies of diabetes management [20]. Others showed that improved patient-provider collaboration leads to improved treatment outcomes since greater agreement on treatment goals and strategies is likely [21]. The latter corresponds 
with the finding in the present study that setting of treatment targets in cooperation with health care providers is preferred by patients with complications.

\subsubsection{Willingness to take medication to attain targets}

Although four out of 10 patients in this study were willing to take tablets until all three targets were attained, it may be difficult for patients to comply for long-time with a regimen of polypharmacy, especially since targets tend to become more strict [22]. However, as also four out of ten would stop medication when complaints might arise, it seems likely that low adherence to medication use might occur more frequently than health care providers suspect. This has also been reported by others [23]. The shift toward patient centeredness in the management of chronic diseases such as diabetes has led to an increased focus on shared decision making between patients and health care providers. However, misunderstandings about participation in prescribing decision between patients and health care providers are common and based on inaccurate assumptions by both [24]. The present study of patients' opinions about taking medication up to target, provides important information for health care providers to reduce such misunderstandings. Males were more likely to take tablets until all three targets had been attained. This gender difference, to our knowledge, has not been described before in patients with diabetes, but related differences in gender have been described elsewhere showing men to be more decisive than women in expressing the desire to know information on impact of medication [25]. Although age was not a determinant for any of the opinions we measured, others showed that older persons with diabetes type 2 usually comply initially with medication advice but will often show non-adherence after some time [26].

This is a robust study on the view of patients in both primary and secondary care in the Netherlands. It assesses the independent associations between a broad range of patients' characteristics and opinions with patients' preferences and perceptions about diabetes treatment. The study has some limitations. Firstly, we presented data on consecutive patients and could not control for possible selection bias. To our knowledge all consecutive patients were approached. There were no eligibility requirements. However, this is a study in both primary and secondary care and mean age, gender and educational level are representative for the Dutch population of people with type 2 diabetes [27] and [28]. But, the results cannot be generalised to non-Caucasians. Secondly, this study did not take into account clustering within practices or outpatient clinics, but since the number of questionnaires returned per practice or clinic were thirteen or less the effect of clustering may not be relevant. Finally, we did not assess health literacy; this might have been an important determinant, especially in elderly people [5]. Besides health literacy could be an explanation for the number of 35 persons that did not complete the questionnaire.

\subsection{Conclusion}

Recommended care for diabetes has shifted over the past decade to an approach that is more patient centered. Although the traditional 'sick-role' has been replaced by a wish for a more concordant approach, in which patients are encouraged to be independent and proactive, this study showed that leaving this role is not so simple for patients. Taking into account the characteristics of those who do not want taking responsibility or taking tablets until all three targets are attained, may be of help to provide more individualized care.

\subsection{Practice implications}

When the diagnosis diabetes has been established, doctors and nurses should ask for patients' opinions on self-management in order to tailor responsibility and treatment goals. They may use the following topics: what is the patient's opinion about taking responsibility for his/her diabetes as much as possible; who should be the preferred person to determine personal treatment targets and how willing is the patient to take medication to attain these targets.

\section{CONFLICT OF INTEREST}

No conflict of interest.

\section{FUNDING}

This study was made possible through a grant of the Dutch Diabetes Research Foundation (grant 2005.13.021). 
Gorter, K.J., Tuytel, G.H., Leeuw, J.R.J. de, Bensing, J.M., Rutten, G.E.H.M. Opinions of patients with type 2 diabetes about responsibility, setting targets and willingness to take medication: a cross-sectional survey Patient Education and Counseling: 2010

\section{DISCLOSURE}

I confirm all patient/personal identifiers have been removed or disguised so the patient/person(s) described are not identifiable and cannot be identified through the details of the story.

\section{ACKNOWLEDGEMENTS}

We thank patients and their primary care providers who participated in this study. Furthermore we acknowledge Ms Rebecca Stellato and Mr Peter Zuithoff for their statistical support.

\section{REFERENCES}

[1] American Diabetes Association, Standards of medical care in diabetes-2008, Diabetes Care 31 (Suppl. 1) (2008), pp. S12-S54. [2] R. Glasgow and R.M. Anderson, In diabetes care: moving from compliance to adherence is not enough, Diabetes Care 22 (1999), pp. 2090-2092.

[3] J. Lawton, O. Parry, E. Peel and M. Douglas, Diabetes service provision: a qualitative study of newly diagnosed Type 2 diabetes patients' experiences and views, Diabet Med 22 (2005), pp. 1246-1251. (17)

[4] A. Vég, U. Rosenqvist and A. Sarkadi, Variation of patients' views on Type 2 diabetes management over time, Diabet Med 24 (2007), pp. 408-414.

[5] L.I. Aljasem, M. Peyrot, L. Wissow and R.R. Rubin, The impact of barriers and self-efficacy on self-care behaviors in type 2 diabetes, Diabetes Educ 27 (2001), pp. 393-404.

[6] M. Heisler, D.M. Smith, R.A. Hayward, S.L. Krein and E.A. Kerr, How well do patients' assessments of their diabetes self-management correlate with actual glycemic control and receipt of recommended diabetes services?, Diabetes Care 26 (2003), pp. 738-743.

[7] P. Jallinoja, P. Absetz, R. Kuronen, A. Nissinen, M. Talja and A. Uutela et al., The dilemma of patients responsibility for lifestyle change: perceptions among primary care physicians and nurses, Scand J Prim Health Care 25 (2007), pp. 244-249. )

[8] L. Kuokkanen and H. Leino-Kilpi, Power and empowerment in nursing: three theoretical approaches, J Adv Nurs 31 (2000), pp. 235-241.

[9] C. Feste and R.M. Anderson, Empowerment: from philosophy to practice, Patient Educ Couns 26 (1995), pp. 139-144. Article

[10] IDF Clinical Guidelines Task Force, Global guideline for Type 2 diabetes, International Diabetes Federation, Brussels (2005)

http://www.sciencedirect.com.proxy.library.uu.nl/science? ob=RedirectURL\&_method=externObjLink\& 1 ocator $=$ url \& cdi $=5139 \&$ issn $=07383991 \&$ origin $=$ article \& zone $=$ art page\& plusSign $=\% 2 B \&$ targetUR $\mathrm{L}=\mathrm{http} \% 253 \mathrm{~A} \% 252 \mathrm{~F} \% 252 \mathrm{Fwww} . \mathrm{idf} .0 \mathrm{rg} \% 252 \mathrm{~F}$.

[11] D. Chyun, K.O. Lacey, D.M. Katten, S. Talley, W.J. Price and J.A. Davey et al., Glucose and cardiac risk factor control in individuals with type 2 diabetes. Implications for patients and providers, Diabetes Educ 32 (2006), pp. 925-939. )

[12] P.H. Winocour, Effective diabetes care: a need for a realistic target, Brit Med J 324 (2002), pp. 15771580.

[13] J. Stewart, D. Kendrick and on behalf of the Nottingham Diabetes Blood Pressure Study Group, Setting and negotiating blood sugar and blood pressure targets with people with type 2 diabetes in primary care; a cross sectional survey, Diabet Med 22 (2005), pp. 683-687.

[14] J.J. Busschbach, J. McDonnell, M.L. Essink-Bot and B.A. van Hout, Estimating parametric relationships between health description and health valuation with an application to the EuroQol EQ-5D, J Health Econ 18 (1999), pp. 551-571.

[15] P. Goddijn, H. Bilo, K. Meadows, K. Groenier, E. Feskens and B. Meyboom-de Jong, The validity and reliability of the Diabetes Health Profile (DHP) in NIDDM patients referred for insulin therapy, Qual Life Res 5 (1996), pp. 433-442.

[16] K. Keller, Encyclopedia of obesity, SAGE Publications, London (2008).

[17] L.M.C. Welschen, E. Bloemendal, G. Nijpels, J.M. Dekker, R.J. Heine and W.A.B. Stallman et al., Selfmonitoring of blood glucose in patients with type 2 diabetes that are not using insulin: a systematic review, Diabetes Care 28 (2005), pp. 1510-1517.

[18] G.C. Williams, Z.R. Freedman and E.L. Deci, Supporting autonomy to motivate patients with diabetes for glucose control, Diabetes Care 21 (1998), pp. 1644-1651.

[19] U. Subramanian, T.P. Hofer, M.L. Klamerus, B.J. Zikmund-Fisher, M. Heisler and E.A. Kerr, Knowledge of blood pressure targets among patients with diabetes, Prim Care Diabetes 1 (2007), pp. 195-198. 
Gorter, K.J., Tuytel, G.H., Leeuw, J.R.J. de, Bensing, J.M., Rutten, G.E.H.M. Opinions of patients with type 2 diabetes about responsibility, setting targets and willingness to take medication: a cross-sectional survey. Patient Education and Counseling: 2010

[20] B.A. Boyer, C. Lerman, T.E. Shipley, J. McBrearty, A. Quint and E. Goren, Discordance between physician and patient perceptions in the treatment of diabetes mellitus: a pilot study of the relationship to adherence and glycemic control, Diabetes Educ 22 (1996), pp. 493-499.

[21] M. Heisler, V. Sandeep, R.M. Anderson, P.A. Ubel, S.J. Bernstein and T.P. Hofer, When do patients and their physicians agree on diabetes treatment goals and strategies and what difference does it make?, J Gen Intern Med 18 (2003), pp. 893-902.

[22] J. Stewart, K. Brown, D. Kendrick and J. Dyas, Understanding of blood pressure by people with type 2 diabetes: a primary care focus group study, Br J Gen Pract 55 (2005), pp. 298-304.

[23] J.A. Cramer, A systematic review of adherence with medications for diabetes, Diabetes Care 27 (2004), pp. 1218-1224.

[24] N. Britten, F.A. Stevenson, C.A. Barry, N. Barber and C.P. Bradley, Factors involved in prescribing decisions in general practice: qualitative study, Brit Med J 320 (2000), pp. 484-488.

[25] R. BeLue, K.D. Taylor-Richardson, J. Lin, A.T. Rivera and D. Grandison, African Americans and participation in clinical trials: differences in beliefs and attitudes by gender, Contemp Clin Trials 27 (2006), pp. 498-505.

[26] J. Tjia, J.L. Givens, J.H. Karlawish, A. Okoli-Umeweni and F.K. Barg, Beneath the surface: discovering the unvoiced concerns of older adults with type 2 diabetes mellitus, Health Educ Res 23 (2007), pp. 4052.

[27] G.P. Westert, F.G. Schellevis, D.H. Bakker de, P.P. Groenewegen, J.M. Bensing and J. Van der Zee, Monitoring health inequalities through General Practice: the Second Dutch National Survey of General Practice, Eur J Public Health 15 (2005), pp. 59-65.

[28] J.A.R. Bruggen van, K.J. Gorter, R.P. Stolk and G.E.H.M. Rutten, Overall quality of diabetes care in a defined geographic region: different sides of the same story, Br J Gen Pract 58 (2008), pp. 339-345. 
Gorter, K.J., Tuytel, G.H., Leeuw, J.R.J. de, Bensing, J.M., Rutten, G.E.H.M. Opinions of patients with type 2 diabetes about responsibility, setting targets and willingness to take medication: a cross-sectional survey Patient Education and Counseling: 2010

\section{TABLES}

Table 1

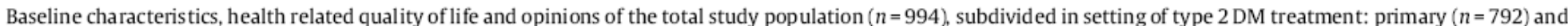
secondary care $(n=202)$.

\begin{tabular}{|c|c|c|c|c|c|}
\hline & $N$ & & Total (\%) & Primary (\% of $n=792$ ) & Secondary ( $\%$ of $n=202$ ) \\
\hline \multirow[t]{4}{*}{ Age } & 994 & Mean $(S D)$ & $65.1(10.3)$ & $65.7(10.4)$ & $62.8(9.5)$ \\
\hline & & $\leq 64$ & 47.8 & 22.4 & 20.1 \\
\hline & & $65-74$ & 32.1 & 57.7 & 66.4 \\
\hline & & $\geq 75$ & 20.1 & 19.9 & 13.5 \\
\hline \multirow[t]{2}{*}{ Gender } & 994 & Male & 53.7 & 53.5 & 54.5 \\
\hline & & Female & 46.3 & 46.5 & 45.5 \\
\hline \multirow{2}{*}{ Ethnicity } & 971 & Western & 97.1 & 97.0 & 97.5 \\
\hline & & Non-Western & 2.9 & 3.0 & 2.5 \\
\hline \multirow{3}{*}{ Education level } & 987 & Low & 20.6 & 20.1 & 22.4 \\
\hline & & Medium & 64.6 & 66.4 & 57.7 \\
\hline & & High & 14.8 & 13.5 & 19.9 \\
\hline \multirow[t]{3}{*}{ Duration diabetes } & 959 & $<5$ years & 43.5 & 50.2 & 17.7 \\
\hline & & $5-10$ years & 28.2 & 28.0 & 28.8 \\
\hline & & $>10$ years & 28.4 & 21.8 & 53.5 \\
\hline \multirow[t]{3}{*}{ Medication diabetes } & 971 & None & 9.8 & 12.2 & 0.5 \\
\hline & & Oral glucose lowering agents (OGLA) & 59.5 & 71.2 & 14.1 \\
\hline & & Insulin with or without OGLA & 30.7 & 16.7 & 85.4 \\
\hline \multirow[t]{2}{*}{ Complications T2DM } & 956 & No & 62.7 & 66.2 & 48.7 \\
\hline & & Yes & 37.3 & 33.8 & 51.3 \\
\hline EuroQol VAS (0-100) & & Mean $(S D)$ & $74.0(15.8)$ & $69.82(17.21)$ & $69.82(17.21)$ \\
\hline \multirow[t]{3}{*}{ Perceived health status } & & Interquartile range & $65-85$ & $67-85$ & $60-80$ \\
\hline & 913 & Poor-average $(0-75)^{\mathrm{a}}$ & 53.5 & 50.9 & 63.4 \\
\hline & & Good $(76-100)^{\mathrm{a}}$ & 46.5 & 49.1 & 36.6 \\
\hline \multirow[t]{2}{*}{ Mobility problems } & 991 & None & 62.3 & 64.9 & 51.7 \\
\hline & & Some/serious & 37.7 & 35.1 & 48.3 \\
\hline \multirow[t]{2}{*}{ Self-care problems } & 991 & None & 95.9 & 96.5 & 93.5 \\
\hline & & Some/serious & 4.1 & 3.5 & 6.5 \\
\hline \multirow[t]{2}{*}{ Pain/discomfort } & 986 & None & 51.3 & 53.3 & 43.5 \\
\hline & & Some/serious & 48.7 & 46.7 & 56.5 \\
\hline \multirow[t]{2}{*}{ Anxiety/depression } & 989 & None & 79.7 & 80.5 & 76.5 \\
\hline & & Some/serious & 20.3 & 19.5 & 23.5 \\
\hline \multirow{4}{*}{$\begin{array}{l}\text { DHP } \\
\text { Barriers to activity }(0-100)\end{array}$} & & Mean $(S D)$ & $85.9(13.2)$ & $87.7(11.7)$ & $79.4(16.8)$ \\
\hline & & Interquartile range & $80.6-94.4$ & $83.3-97.2$ & $69.4-91.7$ \\
\hline & 929 & No dysfunction $(89-100)^{a}$ & 48.5 & 53.1 & 31.3 \\
\hline & & Dysfunction $(0-88.9)^{\mathrm{a}}$ & 51.5 & 46.9 & 68.7 \\
\hline \multirow{4}{*}{$\begin{array}{l}\text { DHP } \\
\text { Eating disinhibition }(0-100)\end{array}$} & & Mean $(S D)$ & $70.1(19.6)$ & $70.3(19.6)$ & $69.5(19.8)$ \\
\hline & & Interquartile range & $60-86.7$ & $60-86.7$ & $60-86.7$ \\
\hline & 968 & No dysfunction $(66.8-100)^{\mathrm{a}}$ & 55.6 & 56.8 & 51.0 \\
\hline & & Dysfunction $(0-66.7)^{\mathrm{a}}$ & 44.4 & 43.2 & 49.0 \\
\hline \multirow{4}{*}{$\begin{array}{l}\text { DHP } \\
\text { Distress }(0-100)\end{array}$} & & Mean $(S D)$ & $88.9(8.1)$ & $89.6(7.4)$ & $86.3(10.0)$ \\
\hline & & Interquartile Range & $85.7-95.2$ & $85.7-95.2$ & $81-92.9$ \\
\hline & 905 & No dysfunction $(90.6-100)^{a}$ & 45.0 & 47.6 & 35.1 \\
\hline & & Dysfunction $(0-90.5)^{\mathrm{a}}$ & 55.0 & 52.4 & 64.9 \\
\hline \multirow[t]{2}{*}{ Opinion glycaemic control } & 962 & (very) Good & 81.4 & 84.7 & 68.8 \\
\hline & & Avarage/(very) poor & 18.6 & 15.3 & 31.2 \\
\hline \multirow[t]{2}{*}{ Opinion weight } & 987 & (much) Too low/good & 38.6 & 41.0 & 29.2 \\
\hline & & (much) Too high & 61.4 & 59.0 & 70.8 \\
\hline \multirow[t]{2}{*}{ Opinion physical exercise } & 988 & (much) Too little & 31.5 & 29.6 & 38.6 \\
\hline & & Just enough/(more than) enough & 68.5 & 70.4 & 61.4 \\
\hline
\end{tabular}

Numbers given in percentages, unless otherwise indicated.

a Dichotomised according to the median. 
Gorter, K.J., Tuytel, G.H., Leeuw, J.R.J. de, Bensing, J.M., Rutten, G.E.H.M. Opinions of patients with type 2 diabetes about responsibility, setting targets and willingness to take medication: a cross-sectional survey. Patient Education and Counseling: 2010

Table 2

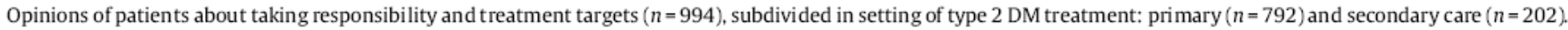

\begin{tabular}{|c|c|c|c|c|c|}
\hline Topic & $N$ & Answering categories & Total $(\%)$ & Primary ( $\%$ of $n=792$ ) & Secondary ( $\%$ of $n=202$ ) \\
\hline \multirow{5}{*}{$\begin{array}{l}\text { Opinion about taking } \\
\text { own responsibility for } \\
\text { (managing) diabetes }\end{array}$} & 953 & I agree very much & 11.0 & 9.9 & 15.2 \\
\hline & & I agree & 50.6 & 49.9 & 53.3 \\
\hline & & I do not care & 29.9 & 32.1 & 21.3 \\
\hline & & I do not agree & 7.9 & 7.4 & 9.6 \\
\hline & & I very much do not agree & 0.6 & 0.7 & 0.5 \\
\hline \multirow{4}{*}{$\begin{array}{l}\text { Opinion preferred person to } \\
\text { determine personal } \\
\text { treatment targets }\end{array}$} & 961 & I do it myself & 1.9 & 1.7 & 2.6 \\
\hline & & My physician or nurse & 41.0 & 42.0 & 37.1 \\
\hline & & In cooperation with my physician or nurse & 48.0 & 47.2 & 51.0 \\
\hline & & I do not care (for treatment targets) & 9.1 & 9.1 & 9.3 \\
\hline \multirow{4}{*}{$\begin{array}{l}\text { Opinion about willingness } \\
\text { to take medication to attain } \\
\text { treatment targets }\end{array}$} & 925 & Until all 3 treatment targets are attained & 44.5 & 47.5 & 43.8 \\
\hline & & Until 2 of the treatment targets are attained & 8.4 & 11.2 & 7.8 \\
\hline & & Until 1 of the treatment targets is attained & 2.8 & 1.1 & 3.2 \\
\hline & & Until complaints or side effects arise & 44.2 & 40.2 & 45.2 \\
\hline
\end{tabular}

Table 3

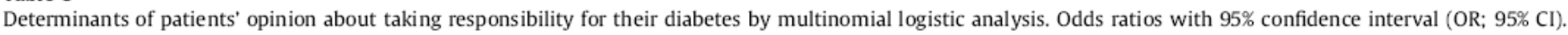

\begin{tabular}{|c|c|c|c|c|}
\hline \multirow[t]{4}{*}{ Outcome } & \multicolumn{4}{|c|}{ Patients' opinion about taking responsibility ${ }^{a}(n=708)$} \\
\hline & \multicolumn{2}{|c|}{ I do not agree } & \multicolumn{2}{|l|}{ I agree } \\
\hline & $n=53$ & Adjusted $^{\mathrm{b}}$ & $n=443$ & Adjusted $^{\mathrm{b}}$ \\
\hline & $(7.5 \%)$ & OR $(95 \% \mathrm{CI})$ & $(62.6 \%)$ & OR $(95 \% \mathrm{CI})$ \\
\hline Age & $53(7.5 \%)$ & $0.95(0.92-0.98)$ & $443(62.6 \%)$ & $0.98(0.96-0.996)$ \\
\hline \multicolumn{5}{|l|}{ Gender } \\
\hline Male & $27(6.7 \%)$ & $0.81(0.42-1.56)$ & $237(59.0 \%)$ & $0.59(0.42-0.84)$ \\
\hline \multicolumn{5}{|l|}{ Education level } \\
\hline Low & $17(12.9 \%)$ & $1.70(0.80-3.59)$ & $65(49.2 \%)$ & $0.57(0.37-0.88)$ \\
\hline \multicolumn{5}{|c|}{ Setting of diabetes treatment } \\
\hline Primary care & $40(7.3 \%)$ & $0.84(0.37-1.92)$ & $333(60.4 \%)$ & $0.59(0.37-0.94)$ \\
\hline \multicolumn{5}{|l|}{ Duration diabetes } \\
\hline$\geq 5$ years & $25(6.2 \%)$ & $0.96(0.93-0.99)$ & $252(62.7 \%)$ & $0.89(0.62-1.28)$ \\
\hline \multicolumn{5}{|l|}{ Mobility problems } \\
\hline Some/serious & $30(11.9 \%)$ & $2.28(1.14-4.54)$ & $146(57.7 \%)$ & $0.95(0.66-1.39)$ \\
\hline \multicolumn{5}{|l|}{ Barriers to activity } \\
\hline Dysfunction & $43(12.2 \%)$ & $3.68(1.65-8.19)$ & $217(61.6 \%)$ & $1.20(0.84-1.74)$ \\
\hline \multicolumn{5}{|l|}{ Disinhibited eating } \\
\hline Dysfunction & $39(12.3 \%)$ & $2.41(1.18-4.95)$ & $189(59.6 \%)$ & $0.89(0.62-1.27)$ \\
\hline \multicolumn{5}{|c|}{ Opinion metabolic control DM2 } \\
\hline Average/(very) poor & $21(17.2 \%)$ & $2.39(1.16-4.91)$ & $68(55.7 \%)$ & $0.87(0.54-1.41)$ \\
\hline
\end{tabular}

a The reference category is: I do not care.

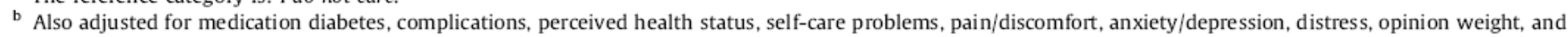
opinion physical exercise. 
Gorter, K.J., Tuytel, G.H., Leeuw, J.R.J. de, Bensing, J.M., Rutten, G.E.H.M. Opinions of patients with type 2 diabetes about responsibility, setting targets and willingness to take medication: a cross-sectional surveyPatient Education and Counseling: 2010

Table 4

Determinants of willingness to take tablets to attain treatment targets by multinomial logistic analysis. Odds ratios with $95 \%$ Confidence Interval (OR; $95 \% \mathrm{CI}$ ).

\begin{tabular}{|c|c|c|c|c|}
\hline \multirow[t]{4}{*}{ Outcome } & \multicolumn{4}{|c|}{ Willingness to take tablets ${ }^{\mathrm{a}}(n=699)$} \\
\hline & \multicolumn{2}{|c|}{ Until all 3 treatment targets are attained } & \multicolumn{2}{|c|}{ Until 1 or 2 of 3 treatment targets are attained } \\
\hline & $n=333$ & Adjusted $^{\mathrm{b}}$ & $n=70$ & Adjusted $^{\mathrm{b}}$ \\
\hline & $(47.6 \%)$ & OR $(95 \% \mathrm{CI})$ & $(10.0 \%)$ & OR $(95 \% \mathrm{CI})$ \\
\hline Age & $333(47.6 \%)$ & $0.99(0.98-1.01)$ & $70(10.0 \%)$ & $1.00(0.98-1.02)$ \\
\hline \multicolumn{5}{|l|}{ Gender } \\
\hline Male & $212(52.9 \%)$ & $1.62(1.17-2.25)$ & $40(10.0 \%)$ & $1.30(0.76-2.23)$ \\
\hline \multicolumn{5}{|l|}{ Education level } \\
\hline Low & $53(43.1 \%)$ & $0.96(0.62-1.48)$ & $14(11.4 \%)$ & $1.08(0.55-2.14)$ \\
\hline \multicolumn{5}{|c|}{ Setting of diabetes treatment } \\
\hline Primary care & $261(47.5 \%)$ & $0.83(0.55-1.24)$ & $52(9.5 \%)$ & $0.67(0.36-1.27)$ \\
\hline \multicolumn{5}{|c|}{ Mobility problems } \\
\hline Some/serious & $103(41.4 \%)$ & $0.76(0.51-1.13)$ & $23(9.2 \%)$ & $0.46(0.24-0.88)$ \\
\hline \multicolumn{5}{|l|}{ Pain/discomfort } \\
\hline Some/serious & $140(42.0 \%)$ & $0.73(0.54-0.98)$ & $42(12.6 \%)$ & $1.07(0.67-1.71)$ \\
\hline \multicolumn{5}{|c|}{ Barriers to activity } \\
\hline Dysfunction & $145(42.3 \%)$ & $0.70(0.50-0.98)$ & $38(11.1 \%)$ & $0.95(0.55-1.64)$ \\
\hline
\end{tabular}

a The reference category is: Only when no complaints or side effects.

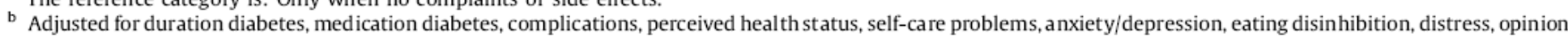
glycaemic control, opinion weight, and opinion physical exercise. 